size of a five-shilling piece, situated over the third rib about midway between the anterior axillary fold and the sternum, or rather nearer the former-in fact, the place of early phthisical development. The respiration of the other lung was unduly exaggerated and the chest was heaving with insuction of the episternal and substernal spaces. I sent him home with orders for him to be kept quiet in a warm room. 1 saw the patient on the next morning when the respirations had increased to 32 per minute, the chest giving the same signs. I suggested a second opinion and the patient was seen by Mr. R.J. Pye-Smith of Sheffield who gave the same opinion as myself. We both agreed that tracheotomy was the proper treatment, but was not immediately necessary unless urgent symptoms should arise. The same night I was called on account of a spasm which had subsided before my arrival. Sabsequently during the night the boy had further difficulty of breathing at intervals, but he slept when he was not so disturbed. The next day I reported the condition to the consultant and it was decided to do the operation the same night. (In passing, I might mention that the child's friends had turned him upside down during the night and had patted his back-a course I had not dared to venture upon. He was very sick, but no foreign body was brought up.)

Before operation, which was performed at 6 P.M. on the 11 th, the patient's temperature was $100^{\circ} \mathrm{F}$, the pulse was 80 , and the respirations were 40 . The condition of the vocal cords did not appear to be a happy one for the adminis. tration of chloroform, and everything, therefore, was close at hand in readiness for an emergency which after a few whiffs of the anæsthetic duly occurred in the form of spasm and cessation of breathing, with coldness of the extremities. Mr. Pge-Smith quickly finished the operation, bat even when the trachea was well opened no respiratory act ensued until after artificial respiration had been continued for some time. The bronchi on the left side of the chest were well searched with long forceps, but nothing could be found. The boy was then held up by the heels and some blood from the bronchi ran out. A large tracheotomy tube was then put in and the opening in the trachea was further kept open by silver sutures with a loop through the cartilages, brought round and tied round the neck behind. The boy was then put back to bed; he was warm and of good colour. Three hours afterwards he was dozing. The temperature was $1008^{\circ}$, the pulse was 80 , and the respirations were 40.

At 6 A.M on the 12th the patient was collapsed; his temperature was $101.8^{\circ}$, his pulse was 92 , and his respirations were 44 , with Cheyne-Stokes breathing. The tube was removed and cleaned. There was considerable pain in the abdomen. Milk and a sedative dranght were given. At 10 A.M. the boy was more comfortable; the bad symptoms were subsiding and he had slept 45 minutes. The temperature was $101.4^{\circ}$, the pulse was 88 , and the respirations were 40 . The patient slept for eight hours during the night after coughing up much glairy mucus. The temperature on the 13th was $100^{\circ}$, the pulse was 94 , and the respirations were 36. Three days after operation (on the 14th) fluid food was taken well. Sume green tenacious mucus was coughed up. The temperature was $99^{\circ}$, the pulse was 100 , and the respirations were 32 . On the 16 th the patient had a comfortable day and night. The stools were examined but no nut was found. The temperature was $98.4^{\circ}$, the pulse was 100 , and the respirations were 30 . On the 17 th the voice passed from a whisper, the respirations being 28 . At 9 A.M. on the 18th two small bits of the husk of the beech-nut were found on the dressing over the tube, which was removed. The temperature was $99^{\circ}$, the pulse was 90 , and the respirations were 28 . On the 20 th the temperature was $98^{\circ}$, the pulse was 96 , and the respirations were 24 . The chest was examined on the 22nd, when respiratory and vocal sounds were found to be deficient in the left lung over the pectoralis major close to the axillary border, otherwise the chest was clearing of rhonchi and sibilli which had been present since the operation. The wound was healthy and the wires were removed. On the 28th the patient came downstairs for the first time, his temperature being $97^{\circ}$, his pulse 84 , and his respirations 20 . The wound in the neck was not quite healed, but the boy was apparently well. Since this time the chest has slowly cleared, but considerable weakness remained for some time. At present one may say that nothing remains to remind him of his adventure but the scar of the tracheotomy wound.

The interesting points of the case are, to my mind, the

following. It is well known that in children paralysis of the adductors takes place from slight causes, and on the face of it I was inclined to question the fact that a portion of the nut had gone into a bronchus. Again, the condition of the child as to "cold" and possible false croup antecedent to the accident could only be cleared up by the friends, and as the patient had once before had some false croup a cold might easily be overlooked if not severe, while his general condition would favour croup. These points must pass through the mind when considering the treatment and they were duly balanced. The only direct evidence was that of the boy, that he had cracked a nut and had tried to swallow it. The sudden oncoming of the attack favoured the presence of a foreign body and the treatment was subsequently proved to have been correct by the small bits of husk coughed up on the dressing. I consider that the success of the treatment in this case was due in a great measure to the excellent nursing which the boy obtained.

Rotherham.

\section{THREE CASES OF PUERPERAL ECLAMPSIA; WITH CRITICAL NOTES ON THE ETIOLOGY, PATHOLOGY, TREATMENT.}

\section{BY J. POLLOCK SIMPSON, M.D. GLASG.}

PUERPERAL eclampsia occurs so rarely in the experience of the private practitioner that it is desirable that all cases met with in practice should be put on record. This may add to the value of experience already gained and may stimulate others to more careful and accurate observation by systematically examining the urine, which is the chief means we have of ascertaining the severity of the case, separating the paraglobulin from the serum-albumin, and noting the relationship between the two as to quantity. Herman has shown that the quantity of the former is greater in those cases where the patients recover, while in the cases of those who die the quantity of serum-albumin is in excess.

As regards the etiology of this disease many theories and hypotheseq have been put forward to account for the convulsions-e.g., the convulsions are the cause of the albuminuria-but in two of the cases described below (Oase 2 and Case 3) I discovered the albuminuria before the convalsions were established-in Case 2 nearly three weeks before the eclampsia occurred and before delivery, and in Case 3 three days previously to delivery and the convulsions. Of recent years a toxæmia or uræmia has usually been believed to be the true cause of this complication of the parturient state; at all events the convalsions are attended by a great decrease in the elimination of urea. Whether urea is the actual excitant of the nerve centres or whether the excitant is a product of decomposition derived from urea has not been satisfactorily explained, but the uræmic theory finds the largest amount of support. The accumulation of the toxins in the blood is due to the faulty elimination by the kidneys of the urea or waste products of tissue metabolism which are much increased in the pregnant state. In nephritis these waste products accumulate rapidly, but pressure also contributes largely, and it is mostly in primiparous cases, where pressure and tension are greatest, that eclampsia occurs. According to statistics 60 per cent. of the cases of eclampsia occur in primiparæ. Constipation, which is the rule in pregnancy, contributes in a great measure to this pathological condition.

The following cases occurred in a busy practice with no assistance from trained nursing, as the patients belonged to the working-class. Notwithstanding the absence of those delicate attentions from a trained nurse-e.g., passing the catheter and measuring the urine-so necessary to exact scientific observation and deduction, the patients all recovered and only one child was lost (in Case 1 , which occurred at the seventh month). Nevertheless these cases have a value of their own, as in one case I was able to follow the history of the patient up to her second confinement with still a trace of albumin in her urine without any untoward symptom and she made a good recovery, In Case 1 the eclampsia was antepartum, in Case 2 it occurred in the second stage of labour, while in Case 3 the eclampsia was post-partum following the delivery of twins. In all the 
cases the result was successful and justified the treatment adopted.

CASE 1.-The patient was a primipara, aged 23 years. I was asked to see her on Nov. 3rd, 1884, as she was said to be in a fit, which, however, had passed off by the time I reached her. She was seven months pregnant with her first child. On questioning her I found that she had gone out the previous day and had come home wet and with damp feet. Cold shivers had set in, so much so that the bed, as she said, shook under her. This was succeeded by violent headache, which the patient described as if the top of her head was being lifted off and on. On the day of my visit her face was noticed to be swollen; her legs were also slightly swollen, but later they became very brawny, especially after her convulsive seizure. She could not recall any of the events of the day. I put her on a mixture of bromide of potassium and chloral hydrate. Next day (the 4th) she had four or five slighter seizures and did not feel at all well; indeed, she was so ill that the question of induction of labour was discussed, but this was put off till the morning of the 7th, when she had the premonitory symptoms of another seizure, for which chloral hydrate (20 grains) was given, and then I introduced an ordinary gum elastic bougie into the uterus and allowed it to remain in situ till labour pains began, nine hours after its introduction, at intervals of 15 minutes. Next day the pains were rather better and I withdrew the bougie. In the evening there was a slight show of mucus when I made a vaginal examination and found the bag of membranes protruding between the lips of the os, which was of the size of a florin, but as the pains were not very vigorous I re-inserted the bougie which accelerated the pains considerably. I was called at $5.30 \mathrm{~A} . \mathrm{M}$. on the 9 th and found on examination per vaginam that the membranes were ruptured and that the breech was presenting at the vulva. I completed the labour, the child being dead when delivered, and the placenta was easily expelled by expression. The child proved to be a female of seven months. The urine on the third day was very scanty and highly albuminous. Its specific gravity, taken on the fourth day, was 1012, and after delivery on the 9th 1020, on the 10th 1023, and on the 12th 1030. The swelling of the face and legs disappeared rapidly after delivery, but the urine was still loaded with albumin on the 12th, otberwise the patient made a good recovery, only complaining of backache and occasionally slight headache. On March 27th, 1885, she was put on tincture of perchloride of iron (five minims), which she continued to take for nine months off and on, but the albumin had not quite disappeared, amounting to a well-marked ring, at her second confinement, which occurred on March 6th, 1886, when she was delivered of a fine, healthy boy without a bad symptom. There was no tendency to flooding either at the first or second confinement, which Spiegelberg says is usual.

CASE 2.-The patient was a primipara, aged 21 years. On March 3rd, 1886, I received a communication about this patient relative to the swelling of her legs and feet. I found her complaining of occasional headache, dimness of vision, and giddiness. The urine was scanty, but there was no pain on passing it. She had not noticed any swelling of her face or puffiness, but her mother had noticed it to exist underneath the eyes. She ate heartily, enjoyed her food, and slept well. She had been sick two days previously for the first time since becoming pregnant. The urine was light-amber-coloured, and on testing it with nitric acid it was found to be loaded with albumin. The specific gravity was not noted. I put her on tincture of perchloride of iron and solution of acetate of ammonia. On the 13th the specific gravity of the urine was 1020 , and it was loaded with albumin. The swelling of the legs was much the same, but the patient's sensations were better, and she thought that the medirine had removed her headache. I received a message on the 2 and to say that she was in labour. On arrival, at 10.50 \& M., I found her walking about; the pains were infrequert ard not very strong. On examination per vaginam I found the os nearly fully dilated, with a head presentation; the membranes were ruptured and the waters had drained away. She complained of headache. The bowels were open. At 2 P.M. the labour was more advanced; the anterior lip of the os was very cedematious. The patient still complained of beadache. At 345 P $\mathrm{M}$. the vertex was mnch lower. As she was lying on the bed I noticed a slight $t$ witching of the right arm which her sister, who was nursing her, thought was shivering, but I at once saw that she was going to have a convulsive seizure. I seized my forceps at once, but before I had time to apply them she was in a strong convalsive fit, her face being drawn up into a sardonic grin; she was blue in the face and struggling for her breath, every moment appearing as if it was to be her last. $I$ at length got the forceps adjusted with little effort and proceeded to extract the child as quickly as safety would permit. By the time I had the head extracted the worst part of the fit had passed off, and I extracted the trunk easily by pressure on the fundus. The child was a female; she was strong and vigorous and cried lustily. The placenta was easily expressed. The patient, having recovered somewhat from the fit, complained loudly of pain. She was semi-conscious, there was no excessive hæmorrhage, and the pulse was 120. When I left her, half an hour after delivery, she knew who I was, but the headache was still severe. I immediately received a message to the effect that she was in another fit; but on my arrival it had passed off, and she was quite rational. This seizure was not quite so strong as the first. I called at $11 \mathrm{P} \mathrm{M}$, and found that she had had another fit which bad lasted for 10 minutes, but that she had had two hours' sleep since, and she was still sleeping at the time of my visit. The pulse was 115. On the 23rd, at my visit, the patient was asleep. The pulse was 112, the face was puffy and swollen, and she complained of severe vertical headache. She had passed no urine since delivery; $I$ therefore drew off one and a half pints of urine, which was straw-coloured, and she felt easier. At $1130 \mathrm{P} \mathrm{M}$. the patient was awake and cheerful, the pulse being 114 and feeble. I drew off about a pint of urine. On the 24th she expressed herself as feeling better. Her headache was less and she passed a considerable amount of urine which was. paler in colour, with a good deal of sediment (urates). The lochia were not offensive. The pulse was 102 . The specific: gravity of the urine was 1025 ; on boiling it, it became almost solid, it contained crystals of urate of soda and tubecasts in abundance, both granular and hyaline. At 11 P.M. the patient was better, her headache being only slight, and she partook of nourishment freely, her pulse being 107. On the 25 th the pulse was 106 , the temperature was $101.8^{\circ} \mathrm{F}$., and the general condition was good. The bowels we re relieved at 11.45 P.M., when the pulse was 100 and tbe temperature was $100 \cdot 4^{\circ}$. On the 26 th the headache was more frontal, the pulse being 105 , the temperature $100^{\circ}$, and the lochia were slightly offensive. Headache was still persistent on the 27th, when the pulse was 99 and the temperature was practically normal. The specific gravity of the urine was 1028 and the albumin was greatly dininished. On the 29th the patient had a relapse from having got out of bed, and there was a tendency to syncope. The pulse was 105 . and the temperature was $99.4^{\circ}$. The urine was scanty and there was an increase of albumin. Its specific gravity was 1030 ; it was darker in colour at $d$ it had a smoky appearance. On the 30 th the headache was still persistent, the pulse being 106, and the temperature $99 \cdot 8^{\circ}$. From this time on till A pril 30th, when I ceased to visit her, the patient's condition varied. She wonld have headache one day which was gone the next. The temperature was variable as well as the urine, which at my last visit still contained a trace of albumin, its specific gravity being 1020 .

OASE 3.-The patient was a primipara, aged 23 years, who was delivered of twins on Oct. 21st, 1894. Three weeks before this occurrence the patient had notic ed some swelling in her feet and legs, but she took no particular notice of it as she thought that it might be due to the press ure of the child On the 18th she had noticed for the first time that her face was swelling. On the 20th I examir ed a specimen of urine and found it to be loaded wilh albomin and solid on boiling; its specific gravity was 1025 On the 21st I received a message to attend the putient. On arrival I found, on examination per vaginam, the os to be of the size of a crown-piece The waters bad all dsained away. The case proceeded slowly for five hours when the verte $x$ was on the perineum. and as the pains were feeble I applied forceps and extracted the head earily and withrut the signs. of a convulsive stizure. When the child was fully born I discovered a second ch.ld in utero. As the bag of waters protrnded throngh the vulva I ruptured it and extracted the second child in the same manner, the atter-birth following. quickly by slight expression without any signs of convulsions, and I began to think that the worst was over The pulse was 136 and the temperature was $1008^{\circ} \mathrm{F}$ About one and a half hours after leaving her the busband 
called to say that she had been having fits almost from the time that I had left her. I prescribed a draght containing chloral hydrate and bromide of potassium and as I had another primiparous case in hand I left her, my assistant watching the case for me. When later I was able to see her I found her insensible, the pulse being 128 and the temperature subnormal. As I had no pilocarpine, and it was late on Sunday evening I administered a diuretic and diaphoretic mixture. My assistant continued to watch the case, administering chloroform occasionally when the fits were trequent and severe. On the 22nd I was called at 5.45 A.M. as the patient was in another fit. I administered chloroform, which quieted her, and this was kept up intermittently till $830 \mathrm{~A} . \mathrm{M}$. The fits began by a slight twitching of the left hand which gradually spread to the right side, when the head was drawn violently to the latter side, the teeth closing by clonic contraction of the jaw, biting the tongue at times and slightly drawing blood; the average duration of the fits was five minutes. Slight pressure on the carotids had an effect upon the duration of the fits, and as their intensity decreased the patient produced a peculiar suction noise with her nose as if in violent inspiration. The temperature was $102 \cdot 5^{\circ}$ and the pulse was 146. As the seizures were beginning to weaken the strength of the patient, as was evidenced by the rapid pulse-rate (150) and the high temperature $\left(105^{\circ}\right)$ at $10 \mathrm{A.M}$. I obtained some pilocarpine and gave her a hypodermic injection of one-fifth of a grain. Soon afterwards profuse diaphoresis set in and at 10.30 P.M. she had not had a fit since. I then drew off 20 ounces of urine, its specific gravity being 1016. The pulse was 136 and the temperature was $99 \cdot 7^{\circ}$. The patient partook freely of milk and other liquid nourish ment. The urine contained one-third per cent. of albumin. On the 25th on my visit I found her maniacal and fanciful, shuddering, and imagining that crawling beasts were about. The temperature was $99.4^{\circ}$ and the pulse was 125 . She remained maniacal for three days. On the evening of the 27 th I gave her 15 grains of sulphonal which caused sleep for about eight hours. On the $28 \mathrm{th}$ she appeared to be much better. She was cheerful, but remembered nothing of what she had gone through. A specimen of urine drawn off and carefully examined was found to contain more para-globulin than serum-albumin, and after separation of the paraglobulin there was a considerable reaction with nitric acid From the 28th to Nov. 11th she made an uninterrupted recovery with the exception of a slight tendency to mania On the latter date there was little reaction with nitric acid; it was scarcely observable with heat.

\section{Pathologr.}

Owing to the small number of cases where a necropsy can be obtained on those patients who die the pathology is not well established. Some authorities have observed a dropsy of the ventricles of the brain which they assume causes pressure and nerve-irritation. Others have noticed an anæmic condition of the brain and nerve centres, while another authority is of opinion that the fits are due to thrombi and to the minute hæemorrhages which they have observed, which they assert are caused by the increased coagulability of the blood in pregnancy, but this is not proved by experience. Most authorities believe that the pathological state is to be found in the kidneys, Bright's disease causing faulty elimination of the waste products of tissue metabolism.

\section{Prognosis.}

The death-rate in this disease is not quite so high as is generally believed. Authorities on the subject are very divergent, ranging from an abnormally low to an abnormally high rate. This map be due in some measure to partisanship, for men who adopt and advccate a certain line of treatment are apt to show off their own results in the most favourable light, while the results of men who adopt another treatment are less favourably commented on. Galabin gives the death-rate as being 30 per cent., but this I am certain is much too high-one-third of this rate I consider nearer the normal. To give a word of hope to the relatives of the patient in a grave complication of this kind is important, and if Herman's view is correct this can be done almost with certainty by systematic examination of the urine where possible. If the albumin is principally para-globulin then with judicious treatment recovery may be predicted with safety, while if the convulsions are due to Bright's disease recovery would be a matter of some doubt.
TREATMENT.

We are apt in this disease as in all others to become empirical in our treatment. A certain line of treatment is very often discredited by the method in which it is employed and carried out, by a want of care and observation on the part of the practitioner in not selecting the proper treatment for the case in question. No special line of treatment is suitable for all cases, inasmuch as many cases of eclampsia will recover speedily with a simple diuretic and diaphoretic mixture and application of heat to the body by means of the hot air or vapour bath or by the simpler means of hot-water bags, but there are other cases in which this is quite inadequate to produce the desired effect-viz., the cessation of the convulsions. One must then adopt more powerful remedies for ridding the system of the effete matter and for allaying the irritability of the cerebro-spinal system. Morphine has been much used of late and has produced good results with different authorities. Lyle ${ }^{1}$ records one death in eight cases lately treated in this manner at the Rotunda, giving a death-rate of $12 \cdot 5$ per cent. Fitzgerald ${ }^{2}$ records two cases treated with morphine and atropine with successful results. The results with this remedy have certainly proved encouraging. Morphine is a powerful anodyne in allaying the irritability of the cerebro-spinal system and so controlling the convulsions, but even with this remedy there are cases where fatal results are likely to follow-e.g., cases of nephritis with renal inadequacy. It is taught in the textbooks of materia medica that opium or its derivatives should not be given in Bright's disease, as it causes convulsions and death; it is possible that this teaching is just as true as it was 20 years ago notwithstanding the seeming contradiction in treating eclampsia with morphine. It has been asserted by Herman, and I think justly, that in the great majority of cases of eclampsia the albumin found in the urine is not due to nephritis, but to altered blood-pressure in the bloodvessels, and when this is so the patient after delivery rapidly recovers and it lestes no evil effects behind; but when the albumin is due to nephritis the condition is much more grave - the kidneys take a much longer time to recover, and the patient is more apt to die than those in the former category. It is just possible that the fatal case recorded by Lyle belonged to the latter class and that morphine is certain to cause fatal results in nephritic cases. It is important, therefore. carefully to examine the urine quantitatively as well as qualitatively, and should the para globulin be in greater proportion than the serum-albumin, then it belongs to the class where altered pressure is the cause of the albuminuria, thus indicating. in my judgment, whether or not morphine should be used. Pilocarpine is a powerful remedy but it is distrusted hy some. In doses of one-fifth of a grain hypodermically it produces profuse diaphoresis in less than 20 minutes, and in my last case of post-partum eclampsia, after diuretics, dia phoretics, chloral. bromide, and chloroform bad all had a fair trial withont in any way curing the convulsions, it acted in the most happy manner. The patient had no more convulsions after its administration, and none of the bad effects, such as profuse salivation, which, according to some, follow its use, occurred. Others have found pilocarpine to produce the same result. Inglis ${ }^{3}$ records a case in which the convulsions ceased immediately after the subcutaneous injection of one-fifth of a grain. Recently treatment by infusion or transfusion of saline solution, either subcutaneously or intravenously, has been much practised and advo. cated. Jardine 4 records 22 cases treated in this manner with three deaths, equal to a death-rate of nearly 14 per cent. Intravenous transfusion I consider bad treatment even in cases of severe post-partum bæmorrhage, as saline solutions can be introduced into the circalation with safety by less dangerons methods-e.g., per rectum and subcutaneously. In all cases of eclampsia I shonld advocate the less heroic methods first, and if no good result be obtained then I should resort to the more powerful remedies, preferring pilocarpine to any other drug in suitable cases. I believe that the great dissimilarity in the methors which are adopted and the results which are obtained in the treatment of this complication of the puerperal state are due to the want of method in apprnaching the treatment of the disease. First of all, if the case permits of this investigation, we must ascertain whether the para-globulin or serum-albumin is in

Brit. Mer Jour., Jan. 19th, 1901. 2 Ibid., Nov. 24th. 1900

4 Transactions of the Obstetrical Society, May 11th, 1901. 
the greater proportion. If we obtain this comparative analysis then the treatment is easy, but if the practitioner be unable to obtuin this data then $I$ should advocate the simpler methods-first, diuretics, diaphoretics, bromide, chloral, and chloroform-before resorting to morphine or hypodermoclysis, keeping in mind the safety of the patient above all other things, and the particular treatment as of secondary importance. If the eclampsia appears in the first months of pregnancy forcible measures in emptying the uterus should be avoided even under chloroform, as one never knows how much damage may be caused to the uterus by this means. Nature is, as a rule, gentle in her methods, therefore the bougie is more likely to act beneficially than is forcible emptying of the uterus. It should be kept in situ so long as to produce powerful and regular contractions. and then withdrawn, to be re-inserted if the pains lag. Venesection is a valuable form of treatment if the patient is plethoric, but to bleed indiscriminately is, in my judgment, bad treatment.

Blandford-street, $\mathrm{W}$.

\section{Clinital atstes:}

\section{MEDICAL, SURGICAL, OBSTETRICAL, AND} THERAPEUTICAL.

\section{A CASE OF PUERPERAL FEVER TREATHD WITH ANTI-STREPTOCOOCIC SERUM ; DEATH.}

By F. W. Thurnam, M.B., O.M. Edin.

A MARRIED woman, aged 34 years, the mother of four children, and who had had three miscarriages, was safely delivered by me, after a normal labour, at 6 P.M. on April 27th, 1901. All appeared to be going on satisfactorily till the fourth day (May 1st) when her temperature, which had been $99^{\circ} \mathrm{F}$. the previous day, was $103.4^{\circ}$, and the lochia were scanty and offensive. Quinine and uterine injections of 2 per cent. solution of creolin reduced the temperature one degree on the following day, bat it rose again till on May 4th it was $103^{\circ}$. Doses of five grains of quinine with 20 minims of solntion of perchloride of iron given every four hours brought it down to $100 \cdot 4^{\circ}$ on the $6 \mathrm{th}$, and, after an intervening rise to $1018^{\circ}$, to $99.8^{\circ}$ on the 9th. After this date there was thrombosis of the left leg and subsequently of the arm on the same side and of the other leg. There was some thickening, probably perimetritis, mostly on the left side. There was diarrhooa from May 7th to 19th, which was checked to some extent by chalk mixture and benzo-naphthol with port wine. A troublesome crop of boils formed on the buttocks and one of them went on to a bedsore, after some

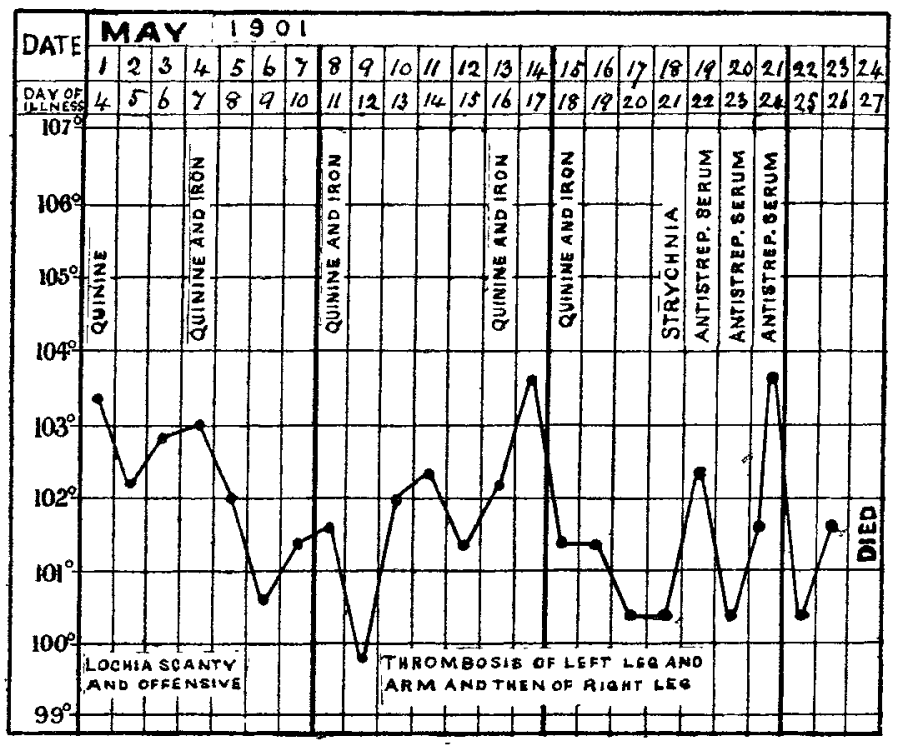

incontinence of urine, which was albuminous. The rigors were numerous and there was more or less delirium, though the tongue remained clean throughout. The pulse and respiration did not correspond with the temperature. From facts which came to my knowledge the source of mischief pointed only too plainly to the nurse who was dismissed on May 4th. On the 14th the temperature was $1036^{\circ}$, falling by the 17 th to $100.4^{\circ}$. On the 19th it was $1024^{\circ}$, when Dr. H. B. Carter saw the patient with me and we decided to try anti-streptococcic serum, which I procured from the Jenner Institute, and at 8 P.M. 20 cubic centimetres were injected, the temperature falling to $100.4^{\circ}$ at noon on the 20th, when $I$ injected 10 cubic centimetres. On the 21 st the temperature was $1016^{\circ}$, so at 11 P.M. I injected 30 cubic centimetres of serum. Half an hour afterwards the temperature was $103 \cdot 6^{\circ}$, but on the next morning it was $1004^{\circ}$, rising on the 23 rd to $101.7^{\circ}$. The patient died at noon on May 24th. The respiration rose gradually from 20 to 60 per minute, latterly with moist râles. From the 18th stry chnia and brandy were necessary.

Having been probably fortunate in this being the only case of puerperal fever which I have had to encounter in my own practice I desire to call attention to the rise of $2^{\circ}$ after the injection on May 21st. I, however, cannot be certain that this was due to the anti-streptococcic serum, and consider that bleeding and the injection of saline solntion would not have been of benefit under the circumstances and that the combination of iron and quinine was on the whole preferable.

New-cross, s.t.

\section{A CASE OF PUNCTURED FRACTURE OF THE SKULL COMPLICATED WITH OTHER SEVERE}

INJURIES; RECOVERY.

By Edward A. Piggont, L.R.C.P. \& S. Edin., L.S.A. Lond。

ON August 30th, 1900, I was called by telegraph some nine miles from my residence to attend the subject of this note. The patient, a builder and contractor by occupation, aged 46 years, in the course of his duties had been unfortunate enough to fall down a deep well; but I cannot do better than quote the following account of the accident from the Brick and Pottery Trades Journal :-

"In August last Mr. J. was engaged in carrying out extensive works at the Manor, Cowlinge, Suffolk. He had employed an experienced well engineer to sink a new well for the water-supply, and being desirous of personally examining the work he requested the well foreman to let him down to the bottom. Unfortunately, Mr. J. went a good deal quicker than he anticipated, for a man employed on the surface to manage the tackle discovered when too late, that Mr. J. bad got into the large bucket before everything was ready. It appeared that the man who had charge of the handle had not attached it to the roller in a proper manner, and $\mathrm{Mr}$. $J$ was dropped no less a distance than 102 feet. His fall was broken by becoming impaled on the bore iron which happened to be still standing in the well. It spiked him through the thigh and held him there until assistance was forthcoming. He was taken to the top, where it was discovered that the thigh was torn open for a considerable distance, and his skull severely fractured."

The patient was removed to his residence from the scene of the accident as soon as practicable, and a cartful examination made at 4 A.M. On the 31 st revealed the following injuries. There was a wound of the scalp some two and a half inches square exposing the bone, situated a little posterior to the left parietal eminence and encroaching on the position of the lambdoid suture. There was no sign of depression or fissure of the external table of the skull, but in the centre of the wound there was a distinct puncture which penetrated the diploë. On the inner side of the right thigh, some three inches above the knee-joint, was a lacerated wound measuring four inches transversely and extending along the inner border of the rectus femoris, beneath the sartorius, and terminating deeply amongst the muscles in the neighbourhood of the apex of Scarpa's triangle; from this wound there was profuse venous hæmorrbage. Fortunately the femora artery escaped injury. The right lumbar region, the right battock, and the whole of the right thigh were one continuous track of ecchymosis - in fact, black with $\in$ ffused blood. The pelvic bones and femur were free from lesion

The condition of the patient at 11 A.M. on August 31st was as follows. He was perfectly unconscious; bis breatbing was laboured and at times was inclined to be stertorous. The 